\title{
Experimental Study on the Tensile Performance of High-strength Blind-bolted T-stub with Endplate Tapping
}

\author{
Ran He ${ }^{1,2, *}$, Xingping Shu ${ }^{1}$ and Zaihua Zhang ${ }^{2}$ \\ ${ }^{I}$ Steel Structure Institute of Civil Engineering College, Hunan University, Changsha 410082, China \\ ${ }^{2}$ College of Civil Engineering, Hunan City University, Yiyang 413000, China
}

Received 14 July 2018; Accepted 29 October 2018

\begin{abstract}
High-strength blind-bolted T-stub with endplate tapping is a new joint that is applicable to the prefabricated joint of steel columns with closed sections and steel beams. The failure mode and force performance of this joint are affected by many factors. In order to disclose the relations of this joint with various parameters, a calculation formula for the bearing capacity of high-strength blind-bolted T-stub with endplate tapping was proposed. The influences of bolt diameter and plate thickness on mechanical performance, failure mode, and bearing capacity were investigated through a unidirectional tensile performance test on $10 \mathrm{~T}$-stub specimens. A nonlinear finite element simulation of specimens was performed, and its results were compared with those of the experiments. Experimental results show that the bearing capacity of the Tstub specimens is positively related with bolt diameter and plate thickness. Compared with an ordinary high-strength bolt, a new shear failure of tapping thread is added. Finite element analysis confirms that the numerical model is reliable and can provide references for parametric analysis. The ratio of calculated results of the proposed formula to the experimental results ranges from $65.1 \%$ to $94.7 \%$, indicating that the calculated results are relatively safe. This study can offer references for the engineering applications of high-strength blind bolts with endplate tapping.
\end{abstract}

Keywords: endplate tapping, high-strength blind bolt, T-stub, prying action

\section{Introduction}

Beam-column joints are an important part of a structure. Thus, they must be equipped with bearing capacity, strength, and appropriate stiffness for structural safety. These joints dissipate the kinetic energy of strong earthquakes through the formation and development of plastic zones. Existing studies have proven that the seismic behavior of semi-rigid joints is better than that of rigid joints. As a typical semirigid joint, bolted joints are flexible for load transmission and can dissipate seismic energy well, thereby preventing the early brittle failure of joints [1].

The parts of high-strength bolted joints are generally fabricated in factories and transported to construction sites for field assembly. In addition to preventing problems of field welding quality, these joints are convenient for transportation and installation. However, ordinary highstrength bolted joints must be tightened up at the steel column with closed sections and require a steel beam to connect them. Installation holes should also be drilled on the steel column with closed sections and then closed again by welding after the installation is finished. Hence, these joints claim heavy construction workloads and cause residual welding stress on steel columns. By contrast, high-strength blind bolts have advantages of unilateral installation, unilateral tightening, and convenient field construction [2-3]

High-strength blind bolts have been investigated

*E-mail address: HERAN01033101@163.com

ISSN: 1791-2377 @ 2018 Eastern Macedonia and Thrace Institute of Technology. All rights reserved. doi:10.25103/|iestr.115.13 extensively [4-7]. Existing studies have focused on selflocking high-strength blind bolts. However, these bolts should be specially customized and easily develop slippage due to their weak resistance to plastic deformation. Hence, they cannot take on dynamic loads directly. High-strength blind blots with endplate tapping, a relatively economic bolt form, form threads on the inner wall of a screw hole on the endplate by using the screw rod of ordinary high-strength bolts; the blind bolts then replace the high-strength nuts by tapping thread. The mechanical characteristics of highstrength blind blots with endplate tapping vary considerably from those of ordinary high-strength bolts.

Relevant studies on high-strength blind bolt with endplate tapping have been reported [8], but most of these studies focused on the shear strength of single bolts. To the best of our knowledge, few experimental studies have been carried out on an actual beam-column T-stub. Failure modes, stress mechanism, and bearing capacity of the high-strength blind bolt with endplate tapping in the tensile state are still unclear.

Therefore, a unidirectional tensile test was performed to analyze the mechanical performance, failure mode, and bearing capacity of a high-strength blind-bolted T-stub specimen with endplate tapping.

\section{State of the art}

Currently, many studies have discussed self-locking highstrength blind bolts. The effects of stud spacing, size of square steel tube, and bolt diameter on the joint strength of self-locking high-strength blind bolts with square steel-tube 
columns were analyzed through a tensile test using 11 specimens [9]. However, the plate of the square column that connected the bolt was thin in this tensile test, where the maximum thickness was $8 \mathrm{~mm}$. Axial tensile and shear tests of the single self-locking high-strength blind bolt were conducted to investigate its tensile strength and bearing capacity [10]. The thicknesses of the connecting plates used in the tests were $10-35 \mathrm{~mm}$. The new self-locking blind bolt presented equal tensile strength with the stress-bearing bolt of the same grade; however, it achieved better shear strength, thus satisfying the requirements of engineering applications. Nevertheless, the precompression of the bolt was not monitored, and finite element model analysis was not performed. Liu Kang et al. [11] proposed the designed formula for the self-locking high-strength blind bolt through failure tests of the square steel-tubule columns under axial and eccentric loads. The self-locking high-strength blind bolt easily developed slippage in the tests. Hence, such bolts are unsuitable for directly bearing dynamic loads. The selflocking high-strength blind bolt was applied to the concretefilled thin-walled steel beam-column joint to explore its failure mode through monotonic loading [12]. This endplate joint based on such high-strength blind bolt had semi-rigid characteristics and could meet requirements on the seismic ductility of most structures. However, the maximum wall thickness of the steel column was only $3 \mathrm{~mm}$. The selflocking high-strength bolted T-stub developed different failure modes compared with the ordinary high-strength bolted T-stub [13]. The former failed in the compressive shearing of the protection casing's branch, whereas the latter failed in the elongation constriction-induced fracture of the screw. Thus, the self-locking high-strength bolt is not very reliable. The responses of the structural system using selflock high-strength bolt to seismic action were explored by performing a pseudo-static test of a framework with two floors and single span [14]. Suggestions on the strength design of the endplate joint for a high-strength blind bolt were provided. The maximum wall thickness of the steel column in this experiment was $8 \mathrm{~mm}$. Although these studies proved the feasibility of the high-strength blind bolt, they mainly focused on the self-locking high-strength blind bolt, which is unsuitable for the direct joint bearing of dynamic loads owing to its complicated manufacturing technique, high cost, and easy development of slippage. On the contrary, high-strength blind bolts with endplate tapping should be studied by considering simple manufacturing techniques and low costs.

High-strength blind bolt with endplate tapping has been recently studied. Liu Yang [15] performed an experimental study and a finite element analysis on the tensile performance of a single high-strength blind bolt with endplate tapping. The tapping plates were thick at 20 and 24 $\mathrm{mm}$. Hence, only one failure mode of specimens rather than all failure modes was observed in the experiment. Two new failure modes of several types of high-strength blind-bolted T-stub with endplate tapping were disclosed through a tensile test based on the Eurocode [16]. Simultaneously, the associated design method and calculation formula of the tensile strength were proposed. However, the tensile action and prying action of the bolt were not measured in the test. Xulin Zhu et al. [17] used a piece of extending plate at bolt holes as a thickening measure of the endplate. In this manner, the low bearing capacity of the tapping endplate in thinwalled parts was controlled, and the tensile performance of T-shaped joints was discussed. The added supporting plate effectively increased the ultimate bearing capacity of $\mathrm{T}$ - shaped joints. However, experimental results were not verified by the corresponding finite element analysis and could not provide references for parametric analysis. These studies did not discuss the applicability of existing calculations in the endplate joint of ordinary high-strength bolt to high-strength blind bolt with endplate tapping.

To address the limitations of existing studies and explore the mechanical performance of high-strength bolt with endplate tapping in a T-shaped beam-column joint in steel structures, a unidirectional tensile test was carried out to observe experimental phenomena and failure modes. Ten high-strength blind-bolted T-stubs with endplate tapping were made. The thicknesses of the T-shaped flange plate and bolt diameter were assumed to be parameters with references to relevant standards and theoretical basis. Moreover, a finite element numerical model was implemented, and a practical calculation formula of tensile strength was established. The study can provide references for the engineering applications of high-strength blind bolt with endplate tapping.

The remainder of this study is organized as follows. Section 3 introduces the experiment and the finite element modeling. Section 4 compares the experimental results with the finite element simulation results concerning tensile performance of the T-stub and development curve of the internal force in a single bolt. The effects of bolt diameter and plate thickness on the experimental results are also discussed. In addition, the validity of the finite element model is verified. Finally, Section 5 provides conclusions.

\section{Methodology}

\subsection{Experimental program}

\subsubsection{Measurement of material properties}

Material properties of the T-stub specimens were measured, whereby the stress-strain relation curve of the T-shaped flange under unidirectional tensile force was detected, and various properties of steel materials, such as elasticity modulus $(E)$, yield strength $\left(f_{\mathrm{y}}\right)$, tensile strength $\left(f_{\mathrm{u}}\right)$, yield strain $\left(\varepsilon_{\mathrm{y}}\right)$, ultimate stain $\left(\varepsilon_{\mathrm{u}}\right)$, and elongation $(\delta)$ were determined. The means of the test results of these specimens were taken as the final values of the different parameters. Experimental results of the material properties were provided by experimental data processing of T-stub, finite element simulation, and theoretical calculation. The experimental results were the mechanical performance indexes of steel materials.

The T-stub specimens were made of Q235 steel. The samples were collected from the flanges of different profile steels. Five groups of plate specimens with different thicknesses were prepared, where three standard specimens with the same size were in each group. Hence, a total of 15 standard specimens were manufactured. All specimens were processed in accordance with the regulations in the Chinese Code Part I of Tensile Test of Metal Materials: Test Method under Room Temperature GB/T 228.1-2010. The specimens of different material properties were processed with a parent metal in the same period. Meanwhile, the mechanical performance of the materials was tested in accordance with relevant regulations.

The material properties were examined by performing a tensile test with a $30 \mathrm{t}$ hydraulic universal testing machine. The loading device for the tensile test and the morphologies of fractional specimens for tensile testing after failure are 
shown in Fig. 2. The experimental results of different specimens are listed in Table.1.

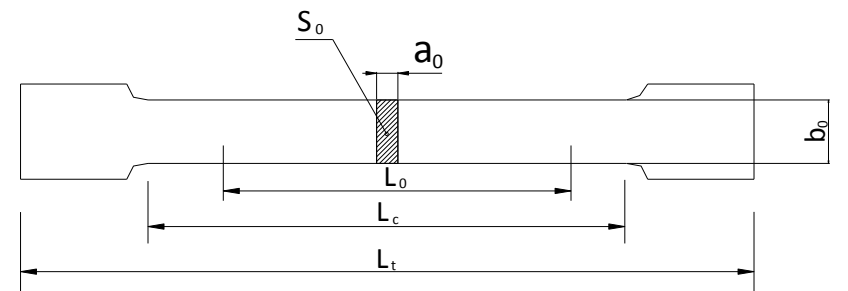

Fig. 1. Standard specimens

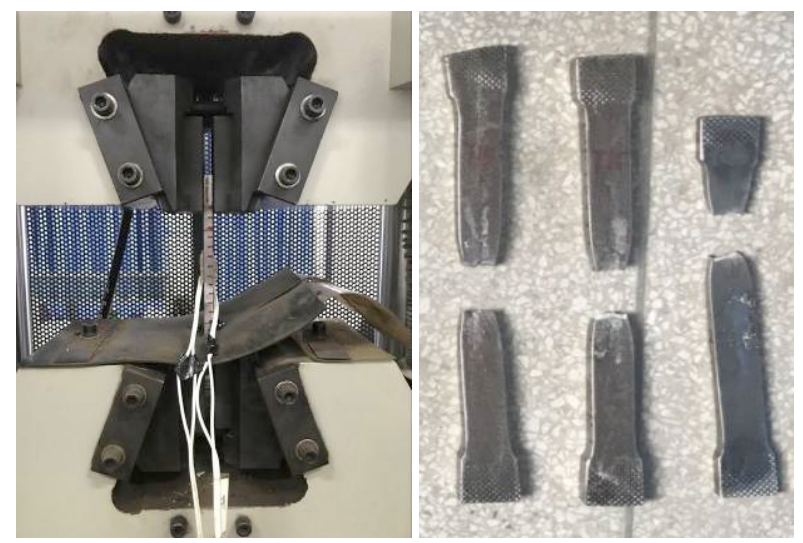

Fig. 2. Loading device for the tensile test and the morphologies of the specimens after failure

Table 1. Experimental results of material properties

\begin{tabular}{c|c|c|c|c}
\hline $\begin{array}{c}\text { Number of } \\
\text { specimens }\end{array}$ & $\begin{array}{c}\text { Thickness } \\
\text { of plate } \\
(\mathbf{m m})\end{array}$ & $f_{\mathrm{y}}\left(\mathrm{N} / \mathrm{mm}^{2}\right)$ & $f_{\mathrm{u}}\left(\mathrm{N} / \mathrm{mm}^{2}\right)$ & $\begin{array}{c}\text { Elongation } \\
\boldsymbol{\delta}(\mathbf{\%})\end{array}$ \\
\hline $\mathrm{T}-10$ & 10 & 319 & 453 & $22 \%$ \\
$\mathrm{~T}-15$ & 15 & 281 & 442 & $26 \%$ \\
$\mathrm{~T}-20$ & 20 & 295 & 441 & $30 \%$ \\
$\mathrm{~T}-25$ & 25 & 281 & 455 & $40 \%$ \\
$\mathrm{~T}-30$ & 30 & 323 & 472 & $25 \%$ \\
\hline
\end{tabular}

\subsubsection{Design of specimens}

Ten high-strength blind-bolted T-stub specimens with endplate tapping (Fig. 3) were designed so as to explore the influences of the thickness of T-shaped flange plate and the bolt diameter on the mechanical performance of the bolt in a T-shaped beam-column joint of steel structures. As shown in Fig. 3, two T-shaped plates were connected into one specimen through two high-strength bolts. One T-shaped plate was the basic T-shaped plate; the web and flange plate were $30 \mathrm{~mm}$ thick, and the hole diameter on the flange plate was $22 \mathrm{~mm}$. No tapping was employed in the holes. The other plate was the testing T-shaped plate; the web was 30 $\mathrm{mm}$ thick, and tapping was employed on the flange plate. The remaining parameters of the specimens are shown in Table 2.

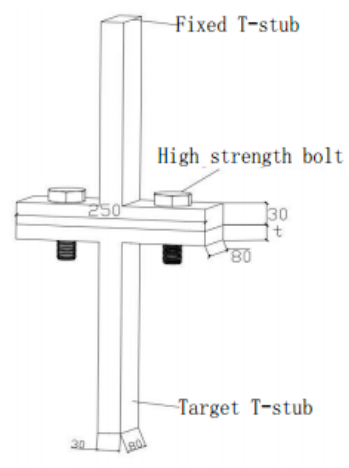

Fig. 3. Structure of the T-stub specimens
Table 2. Parameters of the T-stub specimens

\begin{tabular}{c|c|c|c|c}
\hline \multirow{2}{*}{$\begin{array}{c}\text { Number of } \\
\text { specimens }\end{array}$} & $\begin{array}{c}\text { Parameters of the testing } \\
\text { T-shaped plate }\end{array}$ & $\begin{array}{c}\text { Parameters of the basic } \\
\text { T-shaped plate }\end{array}$ \\
\cline { 2 - 5 } & $\begin{array}{c}\text { Thickness of } \\
\text { flange plate } \\
\text { t/mm }\end{array}$ & $\begin{array}{c}\text { Diameter of } \\
\text { screw hole } \\
\text { D/mm }\end{array}$ & $\begin{array}{c}\text { Thickness of } \\
\text { flange plate } \\
\text { /mm }\end{array}$ & $\begin{array}{c}\text { Diameter of } \\
\text { screw hole } \\
\text { D/mm }\end{array}$ \\
\hline D16-T10 & 10 & 16 & 30 & 22 \\
D16-T15 & 15 & 16 & 30 & 22 \\
D16-T20 & 20 & 16 & 30 & 22 \\
D16-T25 & 25 & 16 & 30 & 22 \\
D16-T30 & 30 & 16 & 30 & 22 \\
D20-T10 & 10 & 20 & 30 & 22 \\
D20-T15 & 15 & 20 & 30 & 22 \\
D20-T20 & 20 & 20 & 30 & 22 \\
D20-T25 & 25 & 20 & 30 & 22 \\
D20-T30 & 30 & 20 & 30 & 22 \\
\hline
\end{tabular}

The high-strength bolts used in the experiment were 8.8grade frictional high-strength bolts in accordance with the product warranty of manufacturers. The yield strength $\left(f_{\mathrm{y}}\right)$ and tensile strength $\left(f_{\mathrm{u}}\right)$ of the bolt rod were 720 and 900 $\mathrm{MPa}$, respectively.

Pretension was applied to the high-strength bolts in accordance with the regulations in China's Design Codes for Steel Structures (GB 50017-2003). The pretension and pretorque values are shown in Table 3.

Table 3. Specifications of high-strength bolt

\begin{tabular}{c|c|c|c}
\hline $\begin{array}{c}\text { Diameter of } \\
\text { screw hole }\end{array}$ & Grade & Pretension /kN & $\begin{array}{c}\text { Pre-torque } \\
\text { /N-mm }\end{array}$ \\
\hline M16 & 8.8 & 70 & 230 \\
M20 & 8.8 & 110 & 455 \\
\hline
\end{tabular}

\subsection{Tensile test of $T$-stub specimens}

The tensile test of T-stub specimens was accomplished in two steps. First, pretension was applied to the high-strength bolt by using a constant torque wrench and then two flange plates were placed in close contact. Second, unidirectional tensile loading through a hydraulic universal testing machine of electro-hydraulic servo was performed on the specimens. All specimens were placed vertically. The upper and lower clamps on the testing machine grasped the web of T-shaped plates directly. Simplified diagrams of the loading device and loading process are shown in Fig. 4. A slow staged loading program was applied, and data were collected every other $20 \mathrm{kN}$.

A load transducer was installed between the bolt and the T-shaped plate to explore the mechanical performance of the high-strength bolt. Moreover, dial indicators were applied on the two bolts and the intersection between the flange plate and the web to observe the deformation of specimens. The space between the flanges of the two T-shaped plates changed as the loading process continued. In other words, deformation of the specimens could be observed.

\subsection{Nonlinear finite element modeling}

\subsubsection{Constitutive model of materials}

The connecting plate and tapping plate in the finite element model were made of Q235 steel. The measured values of yield strength and ultimate tensile strength in Table 1 were applied. The elasticity modulus $(E)$ was $2.06 \times 10^{5} \mathrm{~N} / \mathrm{mm}^{2}$, and the Poisson's ratio was 0.3 . The constitutive relationship employed the twofold linear model and conformed to the von Mises yield criterion and relevant flow rule. The stressstrain relation curves of steel materials are shown in Fig. 5a. The high-strength bolts were 8.8-grade. The stress-strain relation curves are shown in Fig. 5 b. 


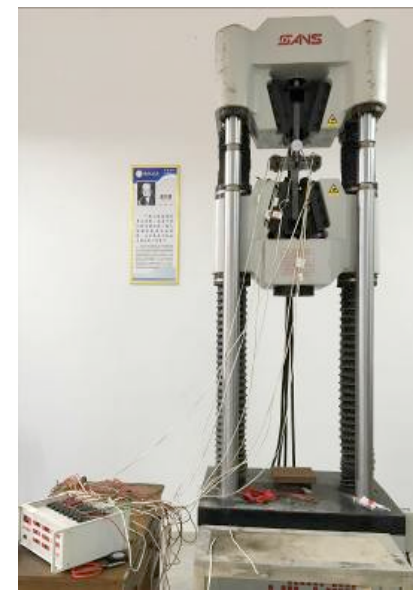

(a) General picture of test

Fig. 4. Loading device in the tensile test

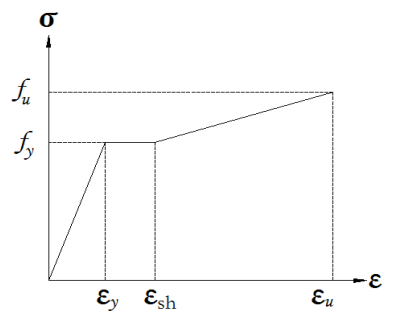

a) steel plate

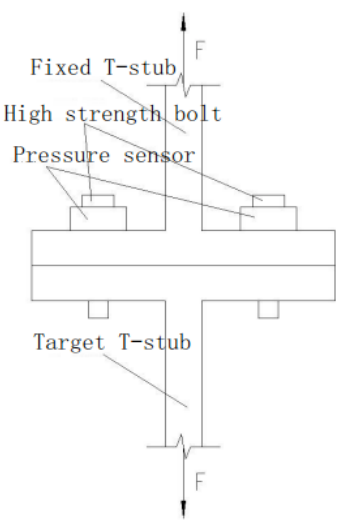

(b) Loading diagram

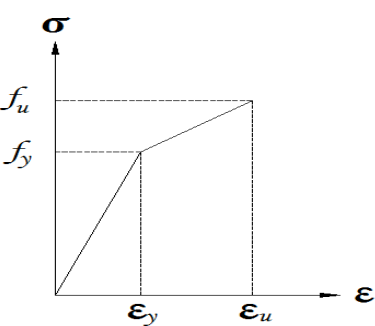

b) high-strength bolt

3.3.2 Types of units, meshing, contact conditions, and boundary conditions

The accuracy and workloads for finite element analysis were directly related to meshing. To construct an accurate and reasonable finite element model, the shape and contact of the constructed model should be considered comprehensively. Appropriate units and grids should be selected and analyzed for accuracy and efficiency. ABAQUS involves multiple types of units. The constructed finite element mode was meshed with hexahedrons, and the C3D8R unit was chosen in the analysis and computation.

In the constructed finite element model, stress conditions at the threads of the high-strength bolts and the threads in the tapping of the flange plate were identified. The meshing densities at these points were relatively high; the meshing densities at the web of T-shaped, basic flange, and tapping flange plates, except for places close to the screw holes, were relatively low. The geometric shape and meshing of the finite element model are displayed in Fig. 6

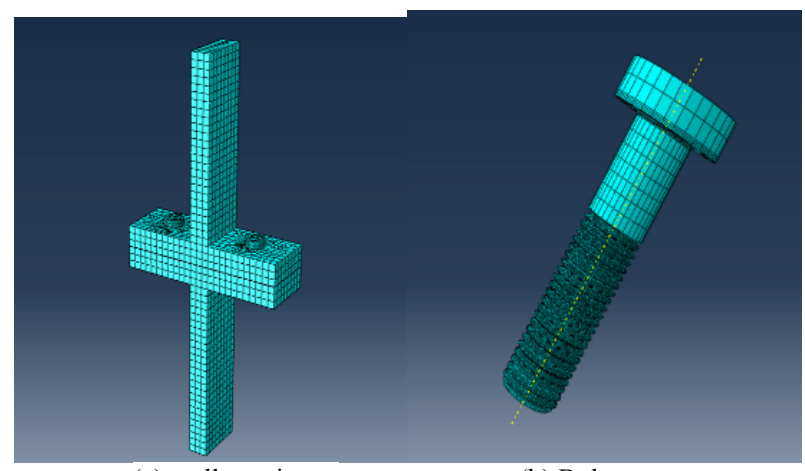

(a) erall specimen

(b) Bolt

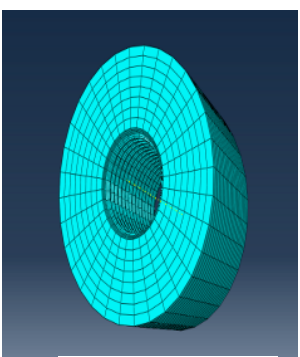

(c) Tapping screw hole

Fig. 6. Meshing of the finite element model

\section{Analysis of Results and Discussion}

\subsection{Experimental phenomena and failure modes}

All specimens mainly present four failure modes in the experiment (Fig. 7). These four failure modes are introduced as follows.

(1) Failure Mode 1: complete yield failure of the flange. Influenced by the pretension of high-strength bolts, two flange plates come into close contact without any seams in the early loading period. However, these plates separate gradually at the intersection between the flange plates and web as loads increase, thereby forming small visible seams. These seams expand dramatically with the increase of loads after reaching the yield loads. Evident plastic deformations are observed in the two flange plates. The loading process is terminated upon the obvious opening state. The corresponding load is equal to the failure load (Fig. 7a).

(2) Failure Mode 2: shear failure of tapping thread in holes on the flange after yield failure of the flange. Experimental phenomena in the elastic stage are consistent with those in Mode 1. The seam between two T-shaped plates expands dramatically after reaching the yield loads. The deformation between these plates represents an evident opening morphology. As the loading continues to reach the failure load, the threads in the holes on the two flange plates develop shear failure. Simultaneously, the flange yields and cannot undertake loads continuously. Thus, the loading process is terminated (Fig. $7 \mathrm{~b}$ ).

(3) Failure Mode 3: yield failure of flange and tensile failure of high-strength bolt. Experimental phenomena in the elastic stage are consistent with those in Mode 1 . The seam between two T-shaped plates expands greatly after reaching the yield loads, and the deformation between plates represents an evident opening morphology. As the loads gradually approach the failure load, the bolts develop tensile failure and the loading process is terminated (Fig. 7c).

(4) Failure Mode 4: tensile failure of high-strength bolt without yield failure of flange. Two flange plates separate gradually without any deformation behavior as the loads increase continuously. The seam between these plates also expands slowly. When the bolts develop tensile failure at the failure loads, the loading process is terminated (Fig. 7d).
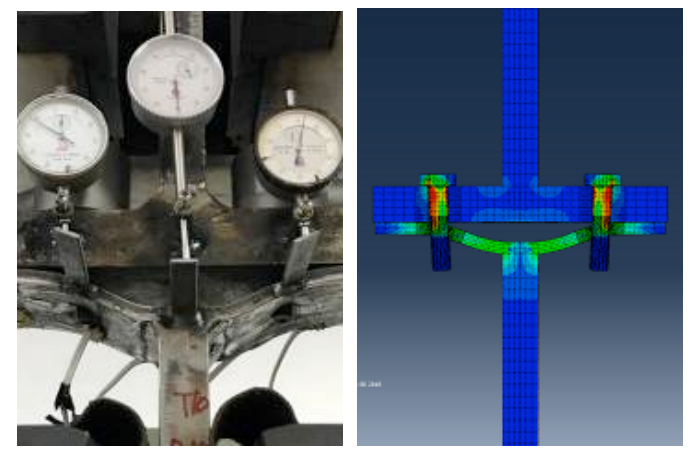


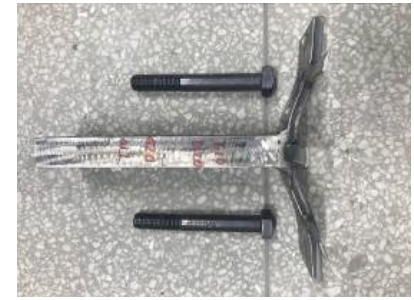

(a) Failure Mode 1: Deformation of the specimens and the finite element model
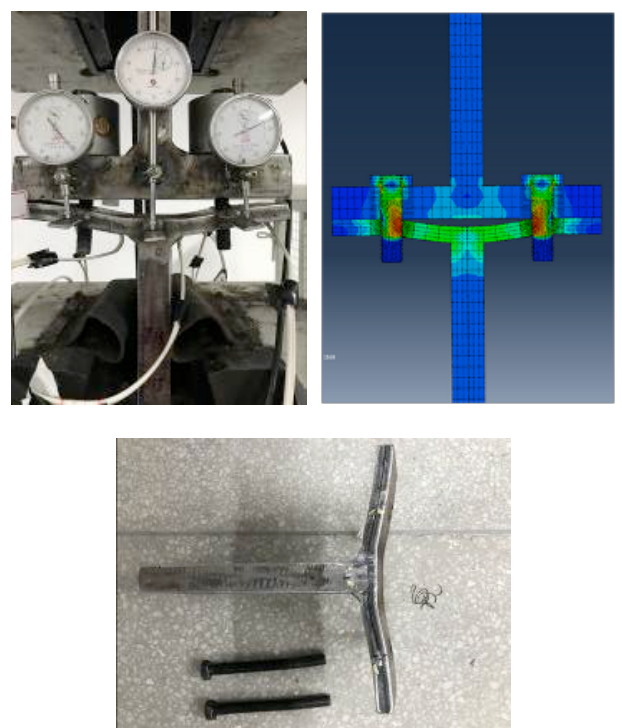

(b) Failure Mode 2: Deformation of the specimens and the finite element model
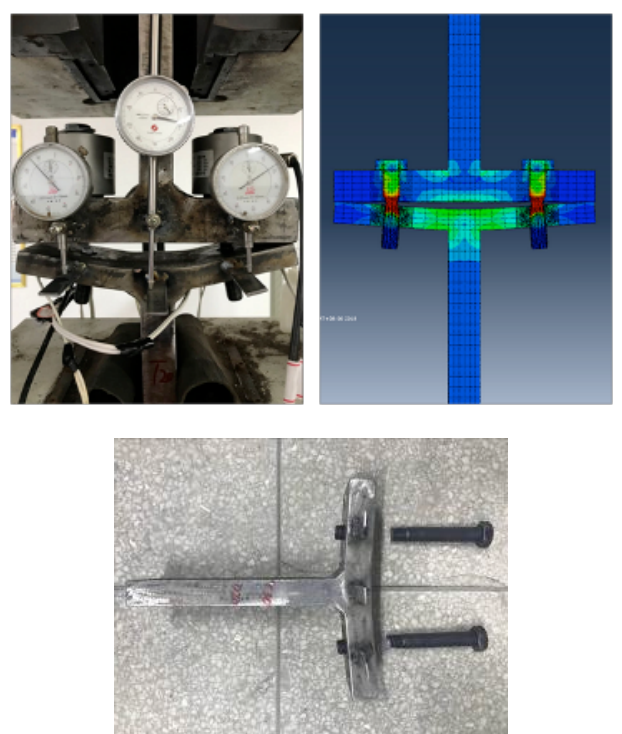

(c) Failure Mode 3: Deformation of the specimens and the finite element model
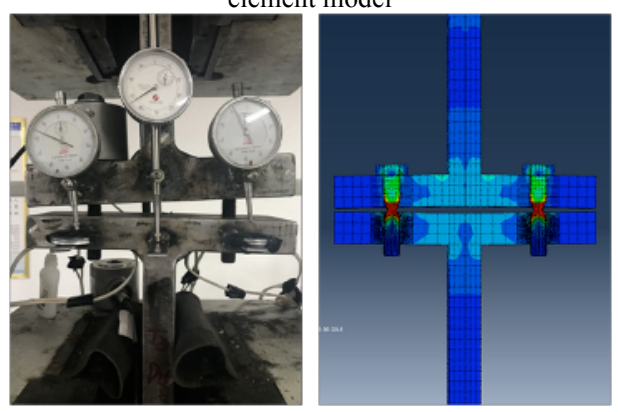

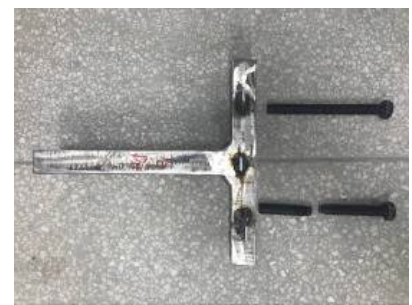

(d) Failure Mode 4: Deformation of the specimens and the finite element model

Fig. 7. Comparison of deformation behaviors between experimental results and finite element simulation

\subsection{Bearing capacity and deformation of the specimens} The load-displacement curves of the specimens are gained based on the finite element analysis and are then compared with those gained from the experiment. The contrast is shown in Fig. 8. The curves are basically consistent with one another. Figures 7 and 8 confirm a good agreement between the experiment and the finite element analysis. The four failure modes in the experiment have corresponding results in the finite element analysis.

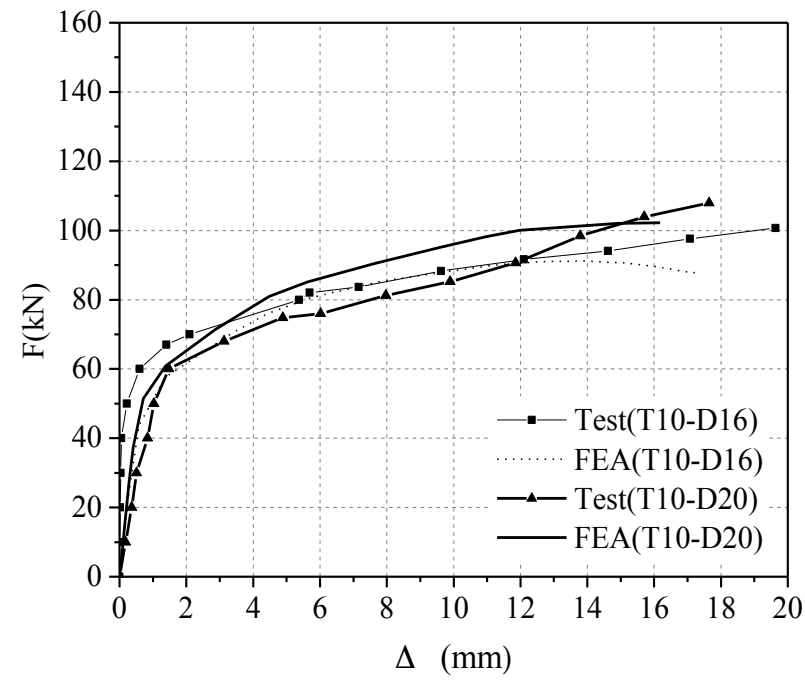

(a) Thickness of tapping flange plate $\mathrm{t}=10$

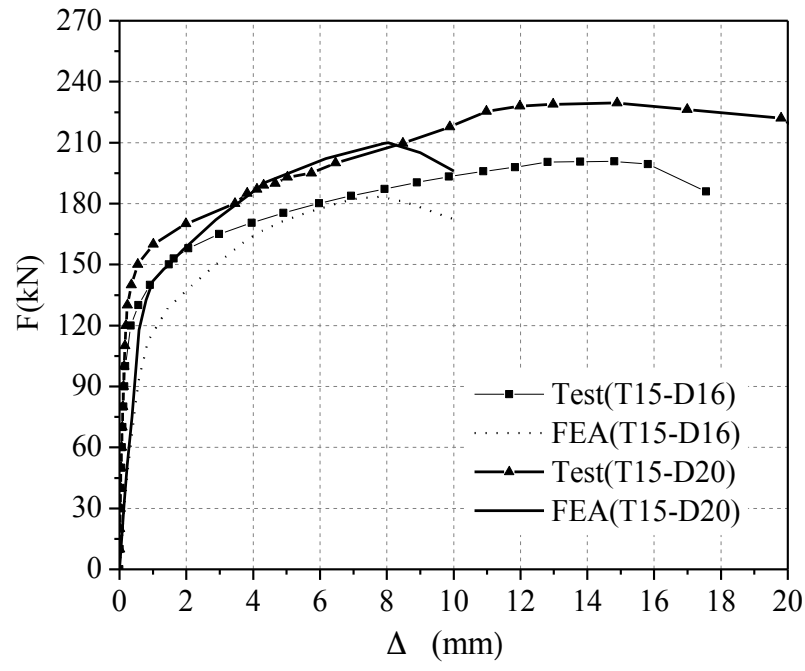

(b) Thickness of tapping flange plate $\mathrm{t}=15$ 


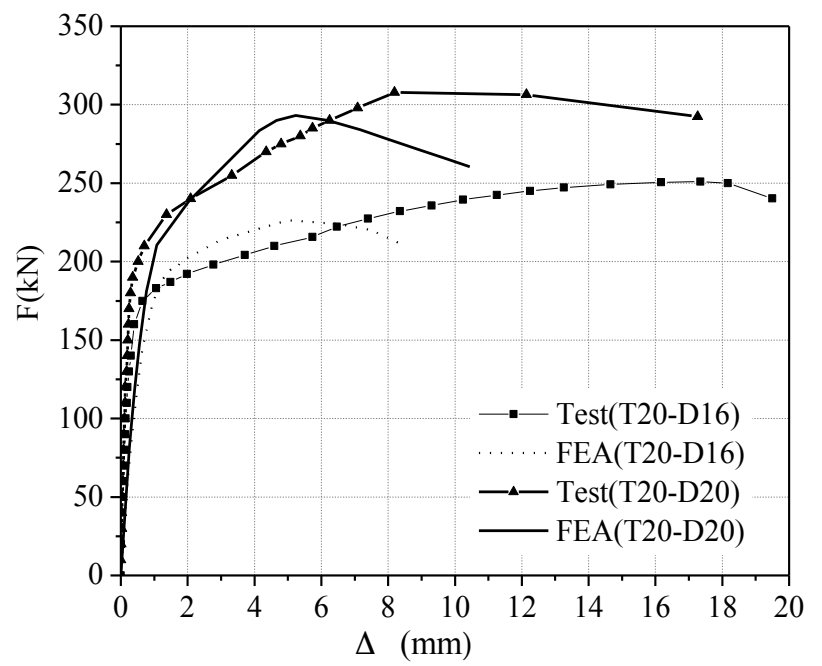

(c) Thickness of tapping flange plate $\mathrm{t}=20$

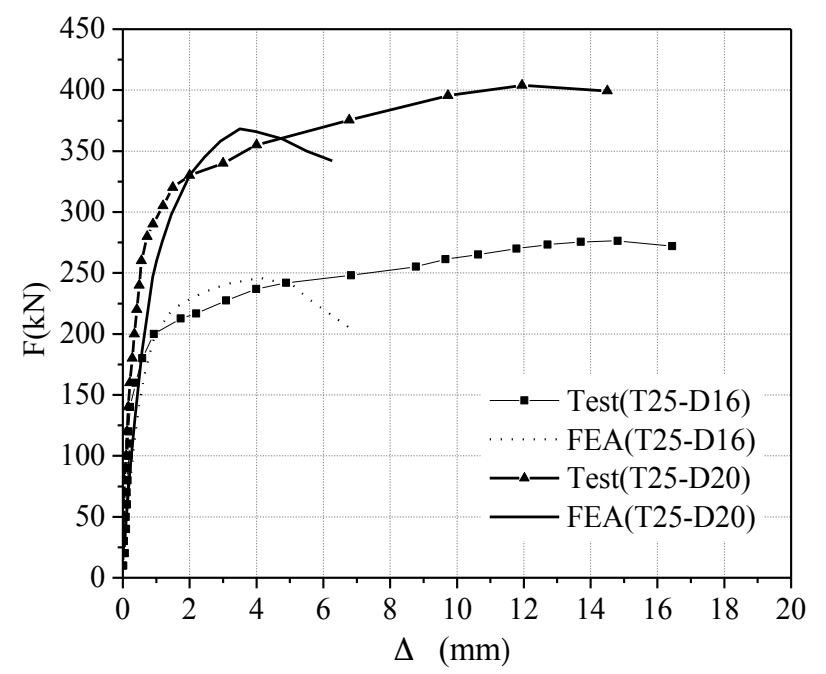

(d) Thickness of tapping flange plate $\mathrm{t}=25$

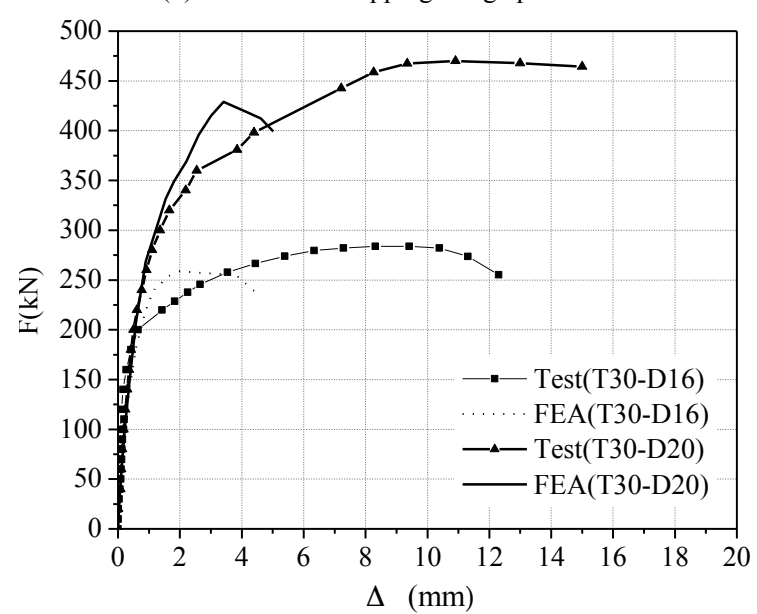

(e) Thickness of tapping flange plate $\mathrm{t}=30$

Fig. 8. Contrast of load-displacement curves in experiment and finite element analysis

The load-displacement curves basically present linear growth in the early loading period. A strengthening stage occurs after reaching the yield load. This stage is accompanied by an accelerating increase of displacement, compared with the increase of loads. The 10 specimens experience evident elastic, elastoplastic, and strengthening stages throughout the loading process, thereby showing good elastoplastic performance.
The yield loads and failure loads of these specimens are shown in Table 4.

Table 4. Bearing capacities of the 10 specimens

\begin{tabular}{c|c|c|c|c}
\hline $\begin{array}{c}\text { Number of } \\
\text { specimens }\end{array}$ & $\begin{array}{c}\text { Yield load } \\
\text { (kN) }\end{array}$ & $\begin{array}{c}\text { Failure } \\
\text { load } \\
\mathbf{( k N )}\end{array}$ & $\begin{array}{c}\text { Yield } \\
\text { displacement } \\
\mathbf{( m m )}\end{array}$ & $\begin{array}{c}\text { Ultimate } \\
\text { displacemen } \\
\mathbf{t} \\
\mathbf{( m m )}\end{array}$ \\
\hline D16-T10 & 63 & 105 & 3.37 & 18.84 \\
D16-T15 & 140 & 201 & 4.65 & 20.98 \\
D16-T20 & 150 & 251 & 7.46 & 28.25 \\
D16-T25 & 202 & 277 & 8.63 & 22.94 \\
D16-T30 & 204 & 284 & 6.69 & 19.30 \\
D20-T10 & 64 & 104 & 4.02 & 17.17 \\
D20-T15 & 162 & 230 & 5.11 & 24.53 \\
D20-T20 & 236 & 312 & 5.18 & 17.02 \\
D20-T25 & 267 & 404 & 8.29 & 21.93 \\
D20-T30 & 348 & 470 & 7.61 & 16.66 \\
\hline
\end{tabular}

The load-displacement curves, bearing capacity, and deformation of different specimens with different parameters are compared.

When the bolt diameter is fixed, the failure mode evolves from Mode 1 to Mode 4 as the flange plates thicken. When the flange plate is excessively thin, the failure mode belongs to Mode 1, and the yield carrying capacity is substantially lower than the shear capacity of tapping on the flange plates [Fig. 8(a)]. When the yield bearing capacity is equivalent to the shear capacity of tapping on the flange plates, the flange plates thicken, and the failure mode belongs to Mode 2 [Fig. 8(b)]. As the flange plates further thicken, the yield-bearing capacity becomes lower than the tensile strength of bolts. Under this circumstance, the shear capacity of tapping on the flange plates is higher than the tensile strength of bolts, and the failure mode belongs to Mode 3 [Fig. 8(c)]. When the thickness of the flange plate exceeds a certain value, the yield-bearing capacity of flange plates is higher than the tensile strength of bolts, and the failure mode belongs to Mode 4 [Fig. 8(d)].

\subsection{Tensile test of high-strength bolts and analysis}

The tensile force $(P)$ that the high-strength bolts undertake is the most important mechanical performance of a T-stub. It is the sum of tensile force $\left(N_{\mathrm{t}}\right)$ and prying action (Q) of bolts originated from external loading. The development process of $P$ can be observed through the force transducer (Fig. 9 and Table 5).

(1) All high-strength bolts show basically consistent variation rule of the tensile force. Pretension is kept constant in the early loading period. The flange plates begin to separate after the external loads reach a certain limit. The curve of the tensile force likewise shows a turning point. The tensile force of the high-strength bolts increases gradually until the joint fails.

(2) Fig. 9(a) shows that when the flange plate is thin, the flange plates yield before the high-strength bolts are fully used. The tensile force $(P)$ of the high-strength bolts is constant throughout the loading process until the thorough yield failure of the flange plates.

(3) Figures 9(b) and 9(c) reveal that the tensile force of the high-strength bolts drops sharply because of the failure of tapping thread on the flange plates. However, the plate does not lose the bearing capacity immediately without obvious signs. The specimens develop brittle failures.

In summary, the thickness of flange plates and the bolt diameter can significantly influence the tensile force of highstrength bolts. 


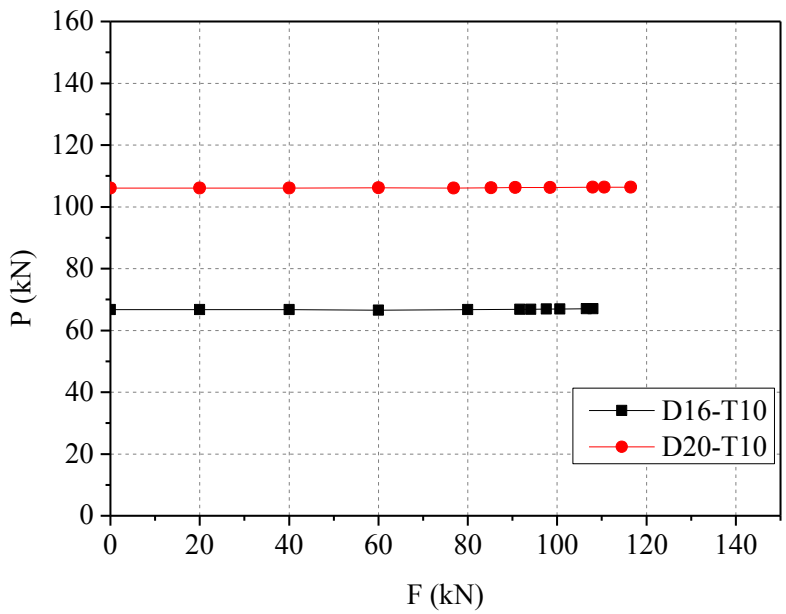

(a)Thickness of tapping flange plate $\mathrm{t}=10$

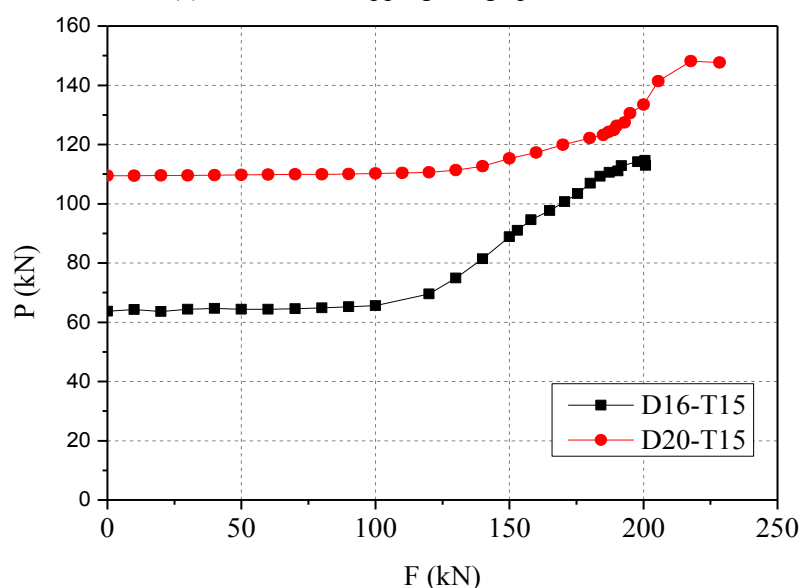

(b)Thickness of tapping flange plate $\mathrm{t}=15$

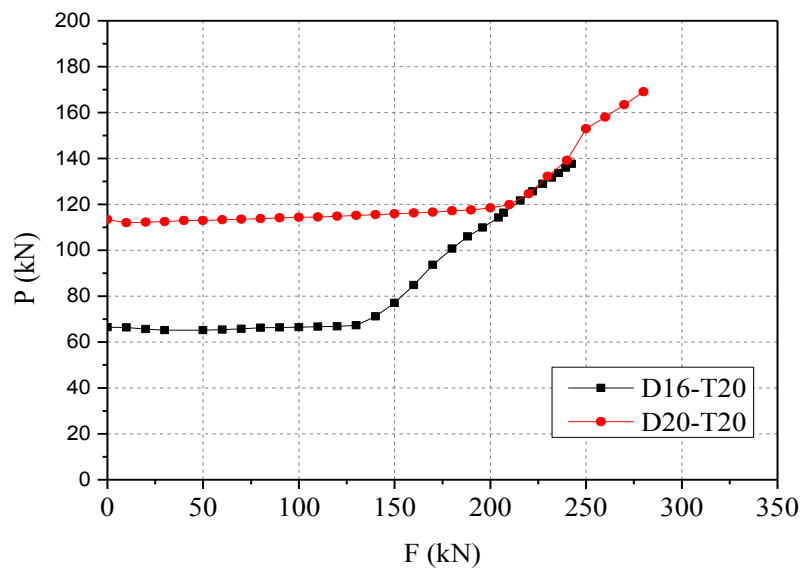

(c)Thickness of tapping flange plate $\mathrm{t}=20$

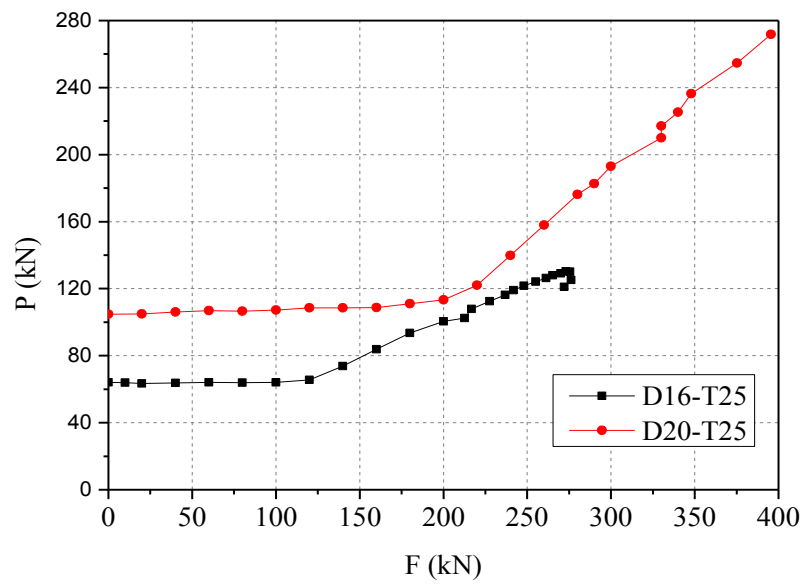

(d)Thickness of tapping flange plate $\mathrm{t}=25$

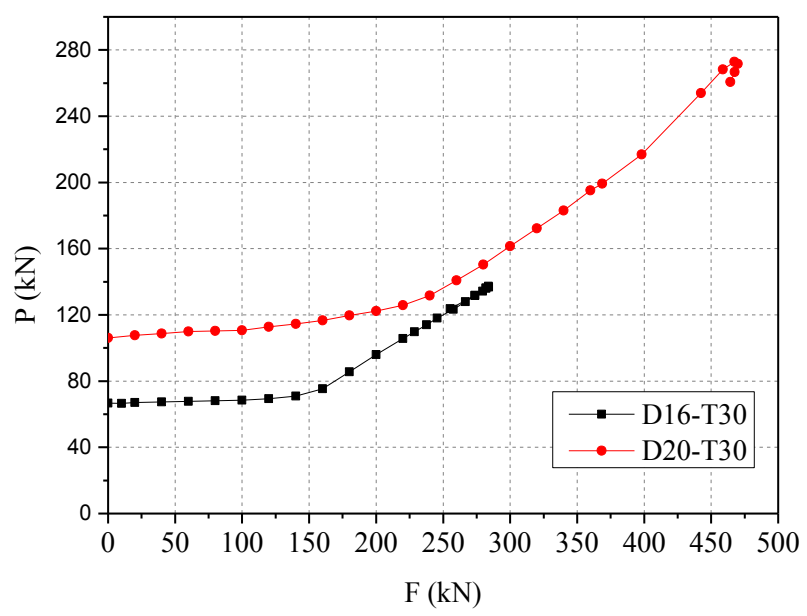

(e)Thickness of tapping flange plate $\mathrm{t}=30$

Fig. 9. Development of tensile force of high-strength bolts

Table 5. Stress analysis of T-stub specimens

\begin{tabular}{|c|c|c|c|c|}
\hline $\begin{array}{l}\text { Number of } \\
\text { specimens }\end{array}$ & $\begin{array}{c}\text { Pretension } \\
(\mathbf{k N})\end{array}$ & $\begin{array}{c}\text { Max } \\
\text { tensile } \\
\text { force of } \\
\text { bolts } \\
(\mathrm{P} / \mathrm{kN})\end{array}$ & $\begin{array}{c}\text { Max external } \\
\text { loads } \\
(\mathbf{k N})\end{array}$ & $\begin{array}{l}\text { Prying } \\
\text { action } \\
(\mathrm{Q} / \mathrm{kN})\end{array}$ \\
\hline D16-T10 & 66.8 & 66.8 & 104.6 & 1 \\
\hline D16-T15 & 63.7 & 114.6 & 201.2 & 28.0 \\
\hline D16-T20 & 66.4 & 141.6 & 251.2 & 33.0 \\
\hline D16-T25 & 64.0 & 138.2 & 276.8 & 0.3 \\
\hline D16-T30 & 66.7 & 142.5 & 284.4 & 0.6 \\
\hline D20-T10 & 108.2 & 108.2 & 103.5 & / \\
\hline D20-T15 & 109.5 & 149.5 & 230.1 & 68.9 \\
\hline D20-T20 & 113.4 & 184.9 & 311.9 & 57.9 \\
\hline D20-T25 & 104.8 & 277.1 & 404.4 & 149.8 \\
\hline D20-T30 & 106.1 & 272.8 & 470.3 & 75.3 \\
\hline
\end{tabular}

4.4 Ultimate bearing capacity of the T-stub specimens under axial tensile force

\subsubsection{Strength of single one-sided bolts under axial tensile force}

The axial stress on a free body connected by a one-sided bolt with single endplate tapping is analyzed. The loadtransferring mechanism of this joint under axial tensile force is shown in Fig. 10a. The axial force is transmitted from the high-strength bolts to the threads in the endplate tapping through the bolt rod. This rod is at least 8.8-grade, and the connecting endplate is often made of Q235 or Q345. Furthermore, the bearing capacity of threads on the rod is significantly higher than that of threads on the endplate tapping. Therefore, only the failure of threads on the endplate tapping is considered in the analysis.

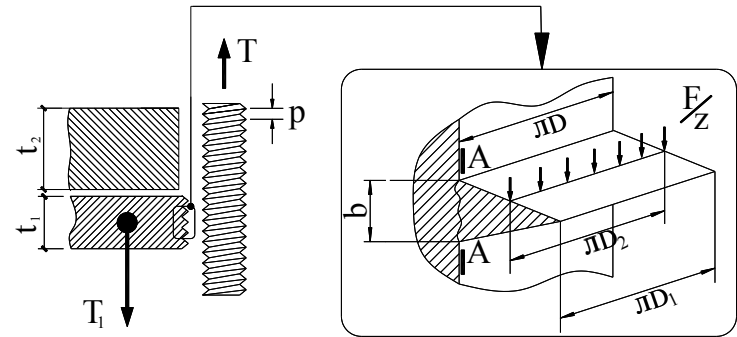

Fig. 10. Transmission mechanism of axial tensile force of the highstrength blind-bolted T-stub with endplate tapping on a single surface

$T_{1}$ is the internal force transferred by the thread profile of endplate tapping. It is determined using the strength conditions of the thread profile under the cantilever stress in Fig. 10(b), the shear strength, and the bending strength of the 
dangerous section A-A. $D$ and $D_{1}$ in Fig. $10(\mathrm{~b})$ denote the outer and inner diameters of the thread profile, respectively. $\mathrm{D}_{2}$ is the pitch diameter, and $\mathrm{b}$ is the height at root of the thread profile $(\mathrm{b}=0.83 p$ for ordinary threads, where $p$ is the screw pitch). Finally, $F$ is the axial force that a round of thread undertakes.

Observing the strength conditions of section A-A can provide.

The shear strength of the section requires:

$$
\frac{F}{\pi b D} \leq f_{V} .
$$

The bending strength of the section requires:

$$
\frac{M}{W}=\frac{F \cdot \frac{D-D_{1}}{2}}{\frac{\pi D b^{2}}{6}}=\frac{3 F\left(D-D_{1}\right)}{\pi D b^{2}} \leq f .
$$

During the test, no second form of damage is found in the thread. As such, the maximum axial tensile force $\left(F_{t}\right)$ that a single round of thread profile might bear is the shear strength of the thread:

$F_{t}=\pi b D f_{v}$

where $f_{v}$ and $f$ are the designed values of shear strength and yield strength of the T-stub specimens, respectively. In the range of thickness of connecting plates $(t)$, the number of the rings of threads is $n=t / p$. The nonuniform coefficient for force transferring among thread profiles and the ultimate bearing capacity $\left(N_{t}^{b}\right)$ of the bolt are considered. Thus, the designed value of tensile axial force of the single bolted joint is

$$
N_{t}=\min \left(\left(k t_{\min } / p\right) F_{t}, N_{t}^{b}\right)
$$

The designed value of tensile strength $\left(N_{t}\right)$ of onesided bolts with endplate tapping is determined using Eq. (4), where $t_{\min }$ is the minimum thickness of plates in highstrength bolts. The thickness of the thread-connecting plate is controlled within 1.5 times the nominal diameter of the thread owing to the nonuniformity of force transferring in thread profiles. In this thickness range of the connecting plate, the nonuniform distribution coefficient $(\mathrm{k})$ of stress on the thread profiles is 0.6 [18].

\subsubsection{Ultimate bearing capacity of $T$-stub specimens} under axial tensile force

The computation units of T-stub specimens under axial tensile force are represented in Fig. 11(a). Three failure modes in Fig. 11 are observed from the T-stub specimens.

Failure of two plastic hinges. The failure mode in Fig. 11(b) appears when the axial stiffness of the bolt is large and the connecting plate is flexible. Plastic hinges are formed at the tapping edges of bolts and the intersection between the connecting plate and the axial load-transferring plate. The stiffness of the plastic hinge is insufficiently small to be the ideal joint mode. Mode 1 in the experiment belongs to this failure mode.
Failure of one plastic hinge. The failure mode in Fig.11(c) occurs when the stiffness of bolts is equivalent to that of connecting plates. Plastic hinge is formed at the edges of intersection between the connecting plate and the axial load-transferring plate as the bolts fail (shear failure of tapping thread or tensile failure of bolts). In this case, the joint develops plastic deformation, and the materials are used fully. This case is an ideal joint mode. Modes 2 and 3 belong to this failure mode.

No failure of plastic hinge. The failure mode in Fig. 11(d) occurs as the stiffness of the connecting plates further increases (i.e., thickening of plates). The tensile failure of bolts is the ultimate state as well. Mode 4 belongs to this failure mode.
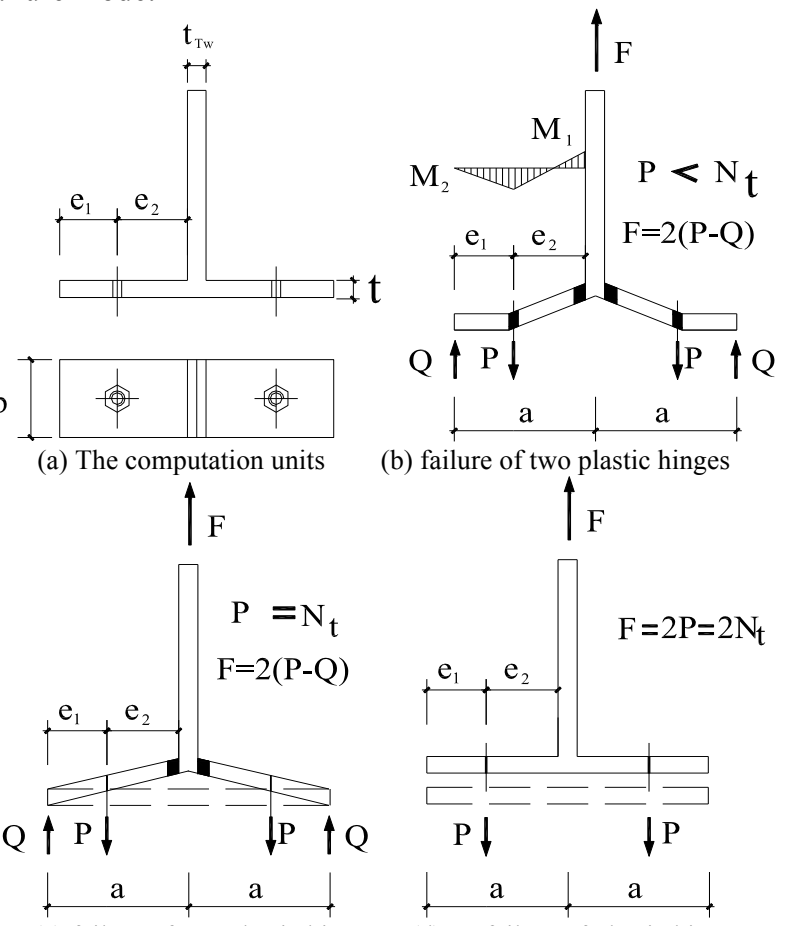

(b) failure of two plastic hinges $\uparrow \mathrm{F}$

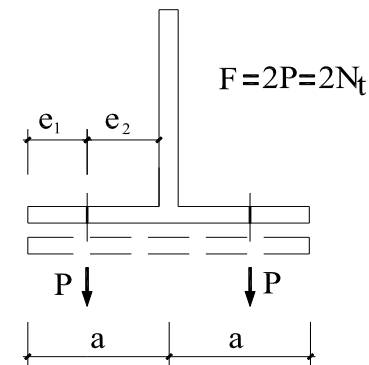

(d) no failure of plastic hinge

(c) failure of one plastic hinge Fig. 11.Load-transferring mechanism of the T-stub specimens under axial tensile force

Figure 11 shows the failure modes where connecting plates may generate plastic hinges. The ultimate shear strength of the T-stub specimens is related to the prying action.

(1) For the situation in Fig. 11(b): failure of two plastic hinges

Two free bodies that connect plates [Figs. 12 (a) and (b)] are selected. The lengths of these bodies are as follows:

$$
e_{1}^{\prime}=e_{1}-d / 2, e_{2}^{\prime}=e_{2}-d / 2,
$$

where $d$ is the diameter of the fastening bolt.

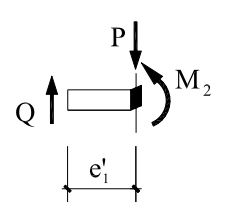

(a)

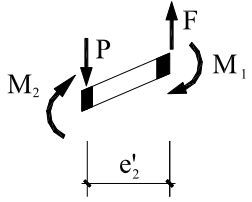

(b) (c)

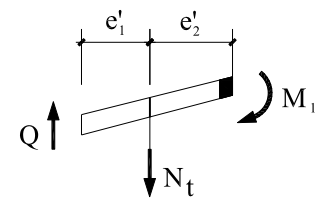

Fig. 12 Free bodies in the T-stub specimens with plastic hinges

The analysis of free bodies provides the following:

$Q=M_{2} / e_{1}^{\prime}$ 


$$
\begin{aligned}
& P=\left(M_{1}+M_{2}\right) / e_{2}^{\prime}, \\
& F=2(P-Q)=2\left(M_{2} / e_{1}^{\prime}-\left(M_{1}+M_{2}\right) / e_{2}^{\prime}\right),
\end{aligned}
$$

where $M_{1}$ is the plastic bending moment of the section at the intersection between the connecting plate and the axial loadtransferring plate, and $M_{2}$ is the plastic bending moment of the net section of the connecting plate at the thread profile, and both can be determined by the section sizes of connecting plates. For the computation units in Fig. 12 (a), $M_{1}=b t^{2} f_{y} / 4$ and $M_{2}=(b-d) t^{2} f_{y} / 4$. Then, Eq. (6) can be rewritten as

$$
P=\frac{(2 b-d) t^{2} f_{y}}{4 e_{2}^{\prime}} .
$$

(2) For the situation in Fig. 11(c): failure of one plastic hinge

Value of prying action (Q) is the key determinant of the ultimate tensile strength under the ultimate state, $P=N_{t}$. Therefore, the free body in Fig.12 (c) is chosen for analysis:

$$
Q=\frac{N_{t} e_{2}^{\prime}-M_{1}}{e_{1}^{\prime}+e_{2}^{\prime}} .
$$

The corresponding ultimate tensile strength $(F)$ of the integral joint is

$$
F=2(P-Q)=2\left(N_{t}-\frac{N_{t} e_{2}^{\prime}-M_{1}}{e_{1}^{\prime}+e_{2}^{\prime}}\right) \text {. }
$$

\section{(3) For the situation in Fig. 11(d): no failure of plastic} hinge

The prying action disappears. Thus, the ultimate tensile strength of the joint can be valued directly as

$F=2 N_{t}$.

Three ranges of thickness of connecting plate correspond with the three failure modes. The thickness intervals of the connecting plates under the three failure modes can be calculated under the designed load $(\mathrm{F})$.

When the prying action is negligible, $M_{1}>N_{t} e_{2}^{\prime}$. When $M_{1}=N_{t} e_{2}^{\prime}$, the first thickness limit of plates $\left(t_{c r 1}\right)$ can be gained:

$$
t_{c r 1}=\sqrt{\frac{4 N_{t} e_{2}^{\prime}}{b f_{y}}} .
$$

Under the failure mode of the two plastic hinges, $P<N_{t}$. Moreover, the second thickness limit of plates $\left(t_{c r 2}\right)$ can be gained:

$$
t_{c r 2}=\sqrt{\frac{4 N_{t} e_{2}^{\prime}}{(2 b-d) f_{y}}} .
$$

Given the fixed connecting layout, the influence of prying action is overlooked in the calculation of the ultimate bearing capacity when the thickness of the connecting plate is $t>t_{c r 1}$ and the ultimate bearing capacity of the joint is determined using Eq. (11). However, the ultimate bearing capacity of the joint should be determined by Eq. (10) when $t_{c r 2}<t<t_{c r 1}$. Furthermore when $t<t_{c r 2}$, it should be determined by Eq. (7). The calculated and experimental results of the ultimate bearing capacity of the T-stub specimens under axial tensile force are shown in Table 6 . The ratio of calculated to experimental results ranges from $65.1 \%$ to $94.7 \%$. Thus, the calculated results are safe.

Table 6. Stress analysis of specimens

\begin{tabular}{c|c|c|c|c}
\hline $\begin{array}{c}\text { Number of } \\
\text { specimens }\end{array}$ & $\begin{array}{c}\text { Calculated } \\
\text { results (kN) }\end{array}$ & $\begin{array}{c}\text { Experimental } \\
\text { results (kN) }\end{array}$ & $\begin{array}{c}\text { Failure } \\
\text { mode }\end{array}$ & $\begin{array}{c}\text { Calculated } \\
\text { results/exper } \\
\text { imental } \\
\text { results (\%) }\end{array}$ \\
\hline D16-T10 & 59.27 & 62.59 & MODE 1 & 94.7 \\
D16-T15 & 130.64 & 200.75 & MODE 2 & 65.1 \\
D16-T20 & 164.67 & 250.98 & MODE 3 & 71.7 \\
D16-T25 & 273.98 & 276.19 & MODE 4 & 99.2 \\
D16-T30 & 273.98 & 283.95 & MODE 4 & 96.5 \\
D20-T10 & 59.27 & 63.8 & MODE 1 & 92.9 \\
D20-T15 & 154.57 & 229.46 & MODE 2 & 67.4 \\
D20-T20 & 218.11 & 307.85 & MODE 2 & 70.9 \\
D20-T25 & 254.15 & 403.97 & MODE 3 & 68.9 \\
D20-T30 & 296.05 & 470.32 & MODE 3 & 68.8 \\
\hline
\end{tabular}

\section{Conclusions}

To disclose the mechanical performance and failure mode of the high-strength blind-bolted T-stub with endplate tapping, the unidirectional tensile test was performed. In this manner, the influences of the bolt diameter and the thickness of connecting plates on the failure mode, bearing capacity, tensile force, and prying action of bolts were identified. The following conclusions could be drawn:

(1) The thickness of the flange plate and the bolt diameter can influence the bearing capacity and failure mode of the T-stub significantly. When the bolt diameter is fixed, the failure mode of specimens evolves from Mode 1 to Mode 4 with the increases in thickness of flange plate. Compared with the ordinary high-strength bolt, the shear failure of tapping thread appears. Hence, parts at Mode 3 should be controlled in practical engineering.

(2) The calculation formula for the ultimate tensile strength of the T-stub is proposed in accordance with the theoretical analysis and the experimental study to address the shear failure of tapping thread. The calculated results are relatively safe and can provide references for practical engineering.

(3) The reliability of the numerical model is verified by performing a finite element analysis. The numerical model can provide references for parametric analysis.

The tensile performance and failure mode of the 10 highstrength blind-bolted T-stub specimens with endplate tapping are studied. The proposed calculation formula and the research conclusions can provide references for practical engineering applications of similar high-strength blindbolted T-stub with endplate tapping. However, only limited mechanical performance indexes are gained because of the small sample size. Further studies on other influencing factors, shear strength of joints, and collaborative action of tensile and shearing forces are still needed. 


\section{Acknowledgements}

This work was supported by the National Natural Science Foundation of China (51778219), the Natural Science Foundation of Hunan Province (2018JJ2020), and the Scientific Research Project of Education Department of Hunan Province (14C0213).
This is an Open Access article distributed under the terms of the Creative Commons Attribution License

\section{References}

1. Wang, Y., "Steel semi-rigid connections-design theory and engineering applications". Beijing: China architecture \& building press, China, 2011, pp. 1-12.

2. Lee, J., Goldsworthy,H.M., Gad, E.F. "BLIND BOLTED T-stub connections to unfilled hollow section columns in low rise structures”. Journal of constructional steel research, 66(8/9), 2010, pp. 981-992.

3. Chen, K.F., Li, Y.H, Lu, J.Y., "Research Progress on the Application of Blind Bolts in Structural Engineering" Jiangsu Construction, 174(1),2016, pp.27-30.

4. Tabsh, S.W., Mourad, S., "Resistance factors for blind bolts in direct tension”. Engineering Structures, 12(19), 1997, pp. 995-1000.

5. Klippel, S. "Recent design developments with blind mechanically operated bolt systems for use with hollow section steelwork". Journal of Constructional Steel Research, 46(1-3), 1998, pp. 267268.

6. Korol, R.M., Ghobarah, A., Mourad, S., "Blind bolting W-shape beams to HSS columns”. Journal of Structural Engineering, ASCE, 119(12), 1993, pp. 3463-3481.

7. Liu, Y., Málaga-Chuquitaype, Elghazouli, A.Y., "Behaviour of beamto-tubular column angle connections under shear loads". Engineering Structures, 42, 2012, pp.434-456.

8. Liu, D.J., "The experimental study and finite element analysis of shear performance of flange tapping high-strength bolt connection". Master thesis of Hunan University, China, 2016.

9. Zhi, Y. W., "Yield and ultimate strengths determination of a blind bolted endplate connection to square hollow section column". Engineering Structures, 111, 2016, pp. 345-369.
10. li, G.Q., Zhang, J.H., "Bearing Performance of domestic class 8.8 self-lock one-side bolt for steel structure". Journal of Architectural Science and Engineering, 35(2), 2018, pp. 1-7.

11. Liu, K., Li, G.Q., "Experimental study on load-bearing capacity of square steel tube bolted splice joints with inner sleeve". Journal of Building Structures, 39(10), 2018, pp.112-121.

12. Wang, J.F., Guo, S.P., "Structural performance of blind bolted end plate joints to concrete-filled thin-walled steel tubular columns". Thin-Walled Structures, 60, 2012, pp. 54-68.

13. Chai, W.J., "Experimental and finite element analysis on mechanic alproperties of single side high-strength bolt with $t$-stub connections". Master thesis of Qingdao University, China, 2017.

14. Wang, J.F., Li, B.B., Wang, D.H., "Cyclic testing of steel beam blind bolted to CFST column composite frames with SBTD concrete slabs". Engineering Structures, 148, 2017, pp. 293-311.

15. Liu, Y., "The experimental study and finite element analysis of the tensile properties of flange tapping high-strength bolt connection". Master thesis of Hunan University, China, 2016.

16. Liu, M., Zhu, X.L., Wang, P.J., "Tension strength and design method for thread-fixed one-side bolted T-stub". Engineering Structures, 150, 2017, pp. 918-933.

17. Zhu, X., Wang, P., Liu, M., "Behaviors of one-side bolted T-stub through thread holes under tension strengthened with backing plate". Journal of Constructional Steel Research, 134, 2017, pp. 5365.

18. Cheng, D.X., “Mechanical design manual (5th edition)”. Beijing: China Machine Press, China, 2011.

19. European Committee for Standardization (CEN). Eurocode 3, "Design of Steel Structures, Part 1.8:Design of Joints", 2003. 